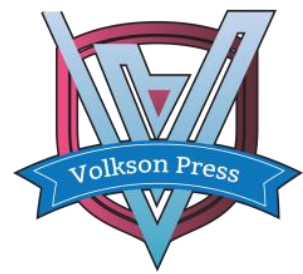

Contents List available at VOLKSON PRESS

Economics \& Management Innovations(EMI)

DOI : http://doi.org/10.26480/icemi.01.2017.63.64

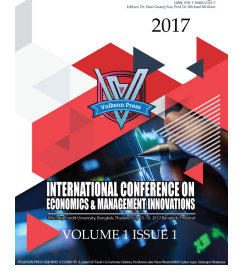

\title{
Study on the Exploitation of Hakka Food Culture Resources in He'yuan
}

\section{YU Tong}

He Yuan Polytechnic, He Yuan, Guangdong, China

email: 86282557@qq.com

This is an open access article distributed under the Creative Commons Attribution License, which permits unrestricted use, distribution, and reproduction in any medium, provided the original work is properly cited.

\section{ARTICLE DETAILS}

\section{Article History:}

Received 02 october 2017

Accepted 06 october 2017

Available online 11 october 2017

Keywords:

He'yuan; Hakka; Food Culture;

Tourism Resources

\section{ABSTRACT}

On the basis of research, this paper summarizes the tourism value of He'yuan Hakka food culture, points out the problems such as obsolete ideas, lack of innovation consciousness and lack of cultural connotation in He'yuan Hakka food culture tourism development, and put forward some suggestions to update the concept, and actively explore the connotation of He'yuan Hakka food culture, improve the participation of food culture and tourism development countermeasures.

\section{Introduction}

He'yuan City is located in the northeast of Guangdong Province, is located in the upper reaches of the Dongjiang River, Dongjiang River Hakka people living center. From the beginning of the Qin Dynasty, due to the impact of the war, the Central Plains region of the Han people by six times southward, came to Jiangxi, Guangdong and Fujian provinces at the junction of the mountain settlements, and gradually formed a relatively stable ethnic group, that is Hakka [1]. Hakka people combined the culture of the Central Plains with the settlement of the culture to create a distinctive Hakka culture, and food culture is an important part of Hakka culture. Hakka ancestors came to the southern mountains, on the basis of the Central Plains food culture, made full use of living materials, learned from the aboriginal diet experience, and created the Hakka dishes [2], and it become an important part of Guangdong three major cuisine. He'yuan City is a pure Hakka area, and He'yuan Hakka cuisine is unique.

Diet is the basic consumption of tourists, and occupies the first among the travel six elements of eat, live, travel, trip, shopping and entertainment [3]. At present, the tourism industry has developed to a higher level of experience tourism, tourists are no longer just satisfied with the sightseeing, but the pursuit of experiential and more participatory cultural tourism, and experience the food culture of different places has become an important cultural tourism content. In order to make full use of the tourism value of Hakka food culture to develop He'yuan Hakka food culture tourism product, this paper summarizes the tourism value of He'yuan Hakka food culture on the basis of research, points out the problems existing in the development of He'yuan Hakka food culture, and analyzes the development countermeasures of He'yuan Hakka food culture tourism resources, so as to provide reference and basis for the development of He'yuan tourism.

\section{Tourism Value of Hakka Food Culture in He'yuan}

\subsection{Investigation on the Feeding Resources of Hakka Food Culture in} He'yuan City

The research group visited the five counties and one district of He'yuan City, and combined with the literature, they carried out a comprehensive investigation on the Heyuan Hakka food culture tourism resources (Table 1). He'yuan Hakka food culture tourism resources can be divided into special dishes, snacks and local specialties three categories. Special dishes were famous for Dongiiang salt baked chicken, Hakka Yong Tau Foo, superior soup with mandarin fish, braised pork, ficus hirta soup and eight knife soup; flavor snacks were famous for the rice noodles with pig feet, pickled radish and lo pet ban; And the local specialty products were famous for the BAWANGHUA rice noodles, dried fish, spicy chicken, ficus hirta, and Hakka wine and so on. Spicy chicken, BAWANGHUA rice noodles, dried fish and
Hakka wine have been developed into the favorite tourist goods, and the others are still in the state to be developed.

Table 1 The survey on He'yuan diet culture tourism resources

\begin{tabular}{|c|c|c|c|}
\hline \multirow{2}{*}{ Area } & \multicolumn{3}{|c|}{ Food Culture Classification } \\
\hline & Specialties & Flavor Snacks & Special dishes \\
\hline $\begin{array}{l}\text { Yuanche } \\
\text { ng } \\
\text { District }\end{array}$ & $\begin{array}{l}\text { Superior soup with mandarin fish, } \\
\text { salty ducks, Dongjiang salt baked } \\
\text { chicken, Hakka stuffed Sambo, } \\
\text { drunk shrimp, folk pots simmer soup, } \\
\text { Hakka Yang Tau Foo, Heyuan cattle } \\
\text { louvers, golden chicken }\end{array}$ & $\begin{array}{l}\text { Rice noodles with } \\
\text { pig feet, pickled } \\
\text { radish }\end{array}$ & $\begin{array}{l}\text { Dried fish, spicy chicken, } \\
\text { ficus hirta, toasted garlic }\end{array}$ \\
\hline $\begin{array}{l}\text { Dongyu } \\
\text { an } \\
\text { County }\end{array}$ & $\begin{array}{l}\text { Crystal chicken, whole cattle } \\
\text { package, all pig set, tofu package, } \\
\text { Xinfeng mandarin fish, ficus hirta } \\
\text { soup }\end{array}$ & Lo pet ban & $\begin{array}{l}\text { Hakka wine, fairylakea tea, } \\
\text { Dan fairylakea tea, Nashi } \\
\text { pear, BAWANGHUA rice } \\
\text { noodles }\end{array}$ \\
\hline $\begin{array}{l}\text { Heping } \\
\text { County }\end{array}$ & $\begin{array}{l}\text { Tofu pills, chop meatballs, grass } \\
\text { carp, whole cattle feast }\end{array}$ & \begin{tabular}{|l|} 
Sweet potato \\
cake, rice noodles \\
with pig feet
\end{tabular} & $\begin{array}{l}\text { Mushrooms, rice noodles, } \\
\text { kiwi, dried persimmon }\end{array}$ \\
\hline $\begin{array}{l}\text { Longchu } \\
\text { an } \\
\text { County }\end{array}$ & $\begin{array}{l}\text { Brewing spring roll, stuffed } \\
\text { mushrooms, Chetian tofu, Lungmo } \\
\text { fish raw }\end{array}$ & $\begin{array}{l}\text { Dried persimmon, } \\
\text { fried fruit }\end{array}$ & $\begin{array}{l}\text { Huoshan brand Longchuan } \\
\text { natural mineral water, } \\
\text { dried fish, beef gluten } \\
\text { cake, Yidu persimmon, } \\
\text { Huangshi Shuangfeng } \\
\text { persimmon }\end{array}$ \\
\hline $\begin{array}{l}\text { Zijin } \\
\text { County }\end{array}$ & $\begin{array}{l}\text { Eight knife soup, crisp pipa shrimp, } \\
\text { braised pork, beef balls }\end{array}$ & \begin{tabular}{|l|} 
Grass ban (grass \\
jelly), Hakka \\
sweet potato bun, \\
fried bun \\
\end{tabular} & $\begin{array}{l}\text { Yongan pepper sauce, day } \\
\text { lily, Longxu tea, Liangguo, } \\
\text { lychee, oriental green tea }\end{array}$ \\
\hline $\begin{array}{l}\text { Lianping } \\
\text { County }\end{array}$ & $\begin{array}{l}\text { Potato pot, Hakka tofu, whole pig } \\
\text { feast, farm feast, Superior soup with } \\
\text { Shuer }\end{array}$ & 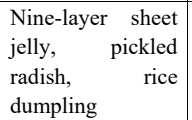 & $\begin{array}{l}\text { Toasted garlic, Yingzui } \\
\text { peach, Yueniang wine }\end{array}$ \\
\hline
\end{tabular}

\subsection{He'yuan Hakka Food Culture Tourism Value}

\subsubsection{Satisfy the Appetite of Tourists}

Diet is the basic consumption of tourists on the road, and the consumption of the local food can meet tourists' appetite, and access to physical and spiritual satisfaction, it is a positive experience in the tourism activities. He'yuan Hakka dishes maintain the traditional Hakka on the basis of food, pay attention to the choice of raw materials, devote particular care to fresh ingredients, wild, non-polluting, and more use of steaming, stewing and other relatively simple cooking methods, to maximize the nutrient retention, and it is meet the concept of modern health, therefore, He'yuan Hakka dishes are welcomed by foreign tourists. 


\subsubsection{Satisfy the Curiosity of Tourists}

Experience the different diet is the most basic motivations for tourists, when arrived at one place, in addition to sightseeing, to taste rare food three meals a day, especially some well-known local dishes, it will stimulate the tourists a strong curiosity. Dongjiang salt baked chicken is a typical example, when outsiders come to Heyuan, in addition to sightseeing outside, they must eat Dongjiang salt baked chicken, and even some people take them away as a gift, and at that time, the Dongjiang salt baked chicken has become the important tourist resource to meet the tourists' curiosity.

\section{The Problems of He'yuan Hakka Food Culture Development}

\subsection{Obsolete Concept and Lack of Awareness of Innovation}

Some of the chefs are obsolete, lack of innovation, blindly pursuing the characteristics"salty, burning, fat, fragrant, cooked, chen" of Hakka dishes, but less to absorb the strengths of other cuisine, resulting in many He'yuan Hakka restaurants including 5-star hotel Some Hakka dishes are still tastes heavier, and the production of extensive, not delicate, low grade, and does not match the demand of modern "green, healthy, taste".

\subsection{Lack of Cultural Connotation Excavation}

At present, the He'yuan Hakka food culture resources tourism development is based on the taste of the basic level food, ignoring the excavation of the Hakka food cultural connotation. He'yuan Hakka cuisine has a very rich cultural connotation, such as the origin of Hakka Yong Tau Foo, in accordance with the custom of the Central Plains, Hakka people need to eat dumplings in the New Year, because the ancient South lack of flour, Hakka people had to use tofu instead of dough, and stuffed the meat into tofu block, thus it formed a unique Hakka characteristics of the dumplings. Hakka Yong Tau Foo reflects the Hakka people on the heritage of the Central Plains culture, but most tourists only know He'yuan Yong Tau Foo is delicious, but have no channels to understand its origins. Therefore, simply based on "eat" to cook the Hakka diet, cannot integrate with He'yuan local tourism industry, either cannot meet the needs of tourists cultural experience.

\section{Development Countermeasures of Hakka Food Culture and Tourism Resources}

4.1 Update the Concept and Improve the Sense of Innovation
Strengthen the training of the chef, so that the chef to accept the "green, healthy, taste" and other fashionable diet concept, on the basis of the advantages of the He'yuan Hakka cuisine selected ingredients, improve cooking methods to absorb the strengths of other cuisines and innovate the Hakka cuisine. For example, you can retain the traditional "fragrant" features, but to give up "salty, fat" and other shortcomings. Learn Cantonese cuisine and Chao'zhou cuisine, pay attention to fine production and the use of fine tableware to improve the He'yuan Hakka dishes taste and grade. 4.2 Actively Explore the He'yuan Hakka Food Culture Connotation To strengthen the excavation and organization of He'yuan Hakka food culture tourism resources, study the story and legend of He'yuan Hakka food culture resources development process and classic dishes [3], and vigorously promote them, thereby increasing the connotation of food culture, to stimulate the desire of visitors to taste and to buy them, enhance the attractiveness of He'yuan Hakka food culture tourism, and further expand the tourism market.

\subsection{To Improve the Participation of Food Culture Tourism Project}

The important difference between experience tourism and sightseeing tourism is the participation of tourists, in some scenic spots, we can design a participatory food culture tourism project, so that visitors can participate in the production of Hakka food. If the production process is more complex, we can make a video, and broadcast in the workshop, so that visitors can understand the food production process, such as the production of Hakka wine. If the production process is relatively simple, we can let visitors directly involved in the production, such as lo pet ban. Tourists involved in the production of the food, and personally produced food, on the one hand, it can meet the curiosity of visitors, on the other hand,

\section{Acknowledgments}

This article was supported by the He'yuan City Philosophy and Social Science 12th Five-Year Plan 2012 Project "He'yuan City Hakka Food Culture Tourism Resources Development Research" (Grant No.: HYSK12Z03).

\section{References}

[1] Liu Zuoquan: The Sources of Hakka. Guilin: Guangxi Normal University Press, (2005).

[2] Li Zhangchun:Hakka Diet Culture Research. Harbin: Heilongjiang People's Publishing House, (2008).

[3] Deng Xiuqin:On the Development of Hakka Food Culture Tourism Resources. Journal of Chongqing University of Science and Technology (Social Science Edition), 2009, (8),p.105-106. 